\title{
Impact of anaesthesia on albumin kinetics during major abdominal surgery
}

\author{
1,2Peckauskas A, ${ }^{1}$ Jovaisa T, ${ }^{1}$ Traskaite V, ${ }^{1}$ Stankunaite J, ${ }^{1}$ Trepenaitis D, ${ }^{1}$ Macas A \\ ${ }^{1}$ Lithuanian University of Health Sciences Kaunas, Lithuania \\ ${ }^{2}$ Centre of Evidence Based Medicine of Lithuanian University of Health Sciences, Lithuania
}

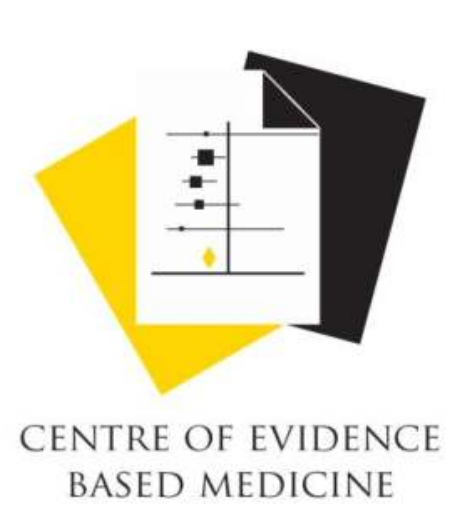

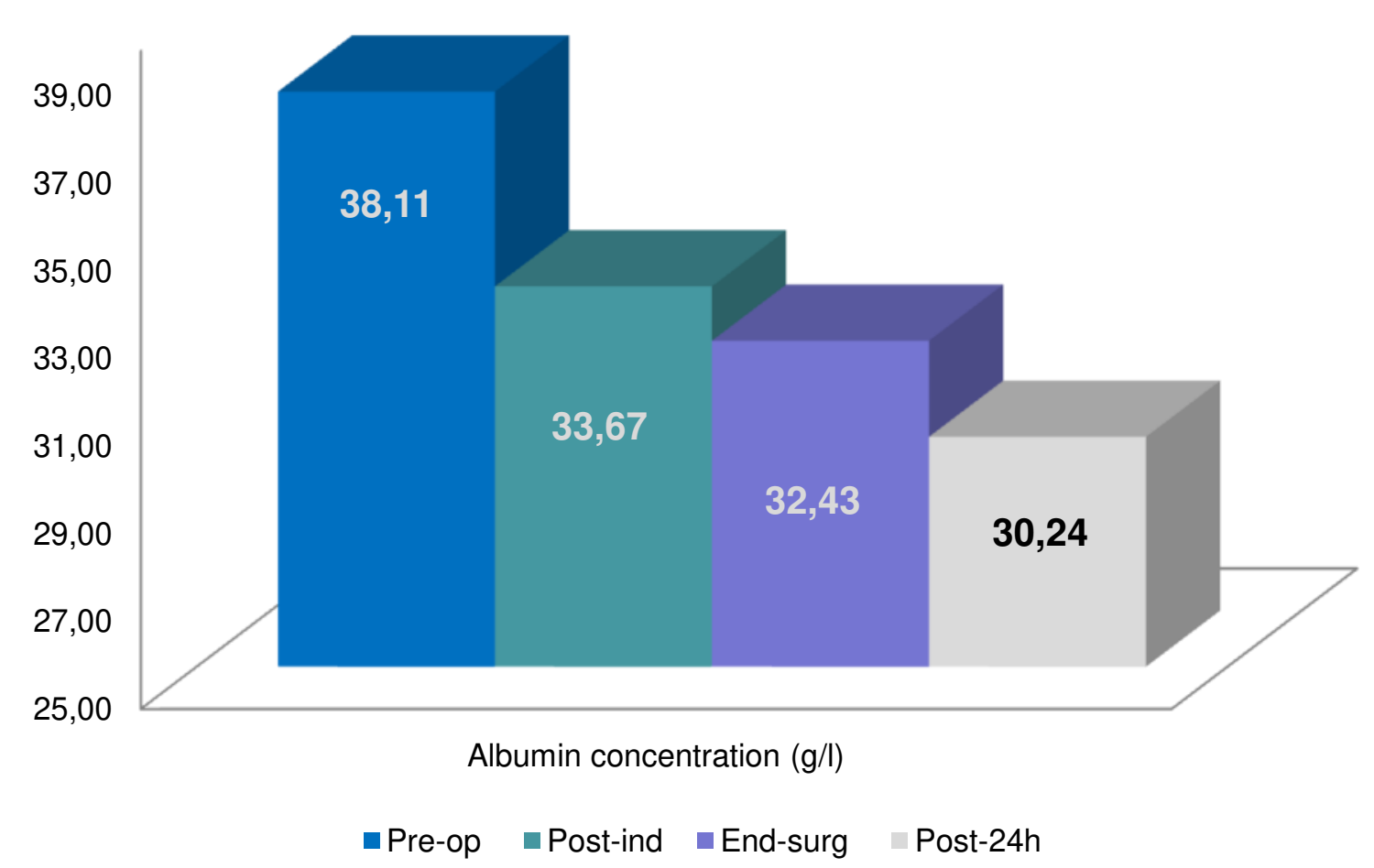

Figure No. 1. Albumin decrease from baseline in $\mathrm{g} / \mathrm{l}$.

\section{Background:}

It is known, that albumin concentration in plasma significantly decreases during major surgery ${ }^{[1,2]}$ and in critical illness mainly due to transcapillary leak and reduced synthesis ${ }^{[3]}$. Current data on the impact of anaesthesia on albumin kinetics is limited and there is a need for further studies that could lead us to improve general anaesthesia techniques as well as perioperative fluid management.

\section{Goal:}

Goal of this study was to assess albumin kinetics during major abdominal surgery.

\section{Materials and Methods:}

A prospective, non-randomized observational study was held in clinic of anaesthesiology of Lithuanian University of Health Sciences Kaunas Clinics. Blood samples of 34 patients who underwent major abdominal surgeries (liver resection, hepatectomy, Whipple procedure, pancreatic resection, gastrectomy) were examined. Investigated blood assays included albumin concentration and arterial blood gases and were performed before surgery, after induction of anaesthesia, at the end of the surgery and 24 hours after the surgery. Statistical analysis was performed using Students t-test. Level of $p \leq 0.05$ was assumed as statistically significant. Approval of Regional bioethics committee was obtained before study initiation. All participants gave informed signed consent to participate in the study.

\begin{tabular}{|c|c|c|}
\hline \multicolumn{3}{|c|}{ Basic characteristics } \\
\hline & Average & SD \\
\hline Duration of surgery $(\mathrm{min})$ & 278,11 & 85,06 \\
\hline Infusion $(\mathrm{ml})$ & 2691,17 & 1304,21 \\
\hline Blood loss $(\mathrm{ml})$ & 565,45 & 471,64 \\
\hline Creatinine preop $(\mu \mathrm{mol} / \mathrm{l})$ & 83,15 & 18,6 \\
\hline Creatinine 24h post $(\mu \mathrm{mol} / \mathrm{l})$ & 103 & 48,86 \\
\hline
\end{tabular}

Table No. 1. Basic characteristics of the sample

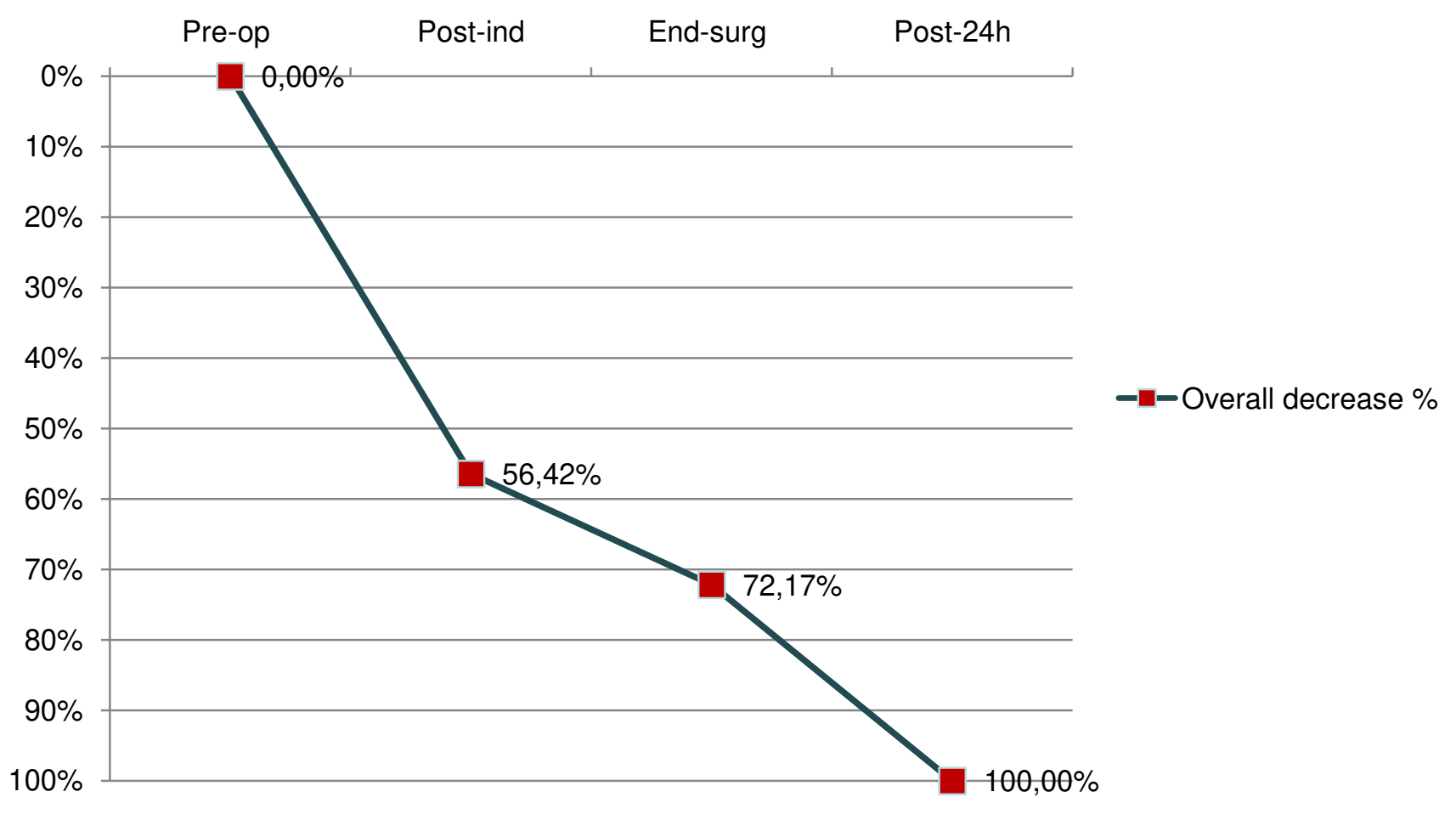

Figure No. 2. Overall albumin decrease in \%

\section{Results and discussion:}

34 patients were involved in the study: 17 males (50\%) and 16 (47.05\%) females. 1 (2.94\%) patient's data was missing. Average age was 67.86 ( \pm 15.86$), 62.42( \pm 15.75)$ in males and $62.13( \pm 15.48)$ in females. Average duration of surgery was $278.11( \pm 85.06)$ minutes whereas average fluid consumption was 2691.18 ( \pm 1304.22$) \mathrm{ml}$. Conservative fluid management with crystalloids was applied, average of 7.33

$\mathbf{m l} / \mathbf{k g} / \mathbf{h}$, according to unit's routine (Table No. 1). There was a statistically significant reduction in albumin concentration immediately following induction of anaesthesia $(38.11 \mathrm{~g} / \mathrm{L}$ at the baseline, to $33.67 \mathrm{~g} / \mathrm{L}$ following

induction, $p=0.000)$, concentration continued to decrease during the surgery $(32.43 \mathrm{~g} / \mathrm{L}, \mathrm{p}=0.000$,) and 24 hours after the surgery $(30.24 \mathrm{~g} / \mathrm{L}, \mathrm{p}=0.000)$. (Fig. No. 1) Overall percentage of albumin concentration reduction from the baseline was $11.66 \%, 14.91 \%$ and $20.65 \%$ respectively. $56.41 \%$ of overall decrease $(7.87 \mathrm{~g} / \mathrm{L})$ was noted immediately after induction (Fig. No. 2). The findings of our study demonstrate, that albumin concentration at the end of the surgery decreased by $13.91 \%$ from the baseline value. A much larger reduction $40 \%$ was demonstrated in the recent study by Norberg and colleagues[1] in a similar patient population. It is uncertain which aspects of peri-operative management lead to such a difference. The most interesting finding is that almost two thirds of overall albumin loss peri-operatively is noted immediately after the induction and it raises the question, what are the main triggers and how we can avoid them. There is a need for further research into preoperative status of patients, anaesthesia induction techniques and physiological changes of the body to fully understand albumin kinetics during initial phases of anaesthesia.

\section{Conclusion}

Our study shows that there is significant and gradual reduction of albumin concentration in major abdominal surgery. Most significant decrease was noted immediately after the induction of anaesthesia.

\section{References:}

1. Norberg A et al. Leakage of albumin in major abdominal surgery. Critical Care (2016) 20:113 DOI 10.1186/s13054-016-1283-8. 2. Norberg A et al. Albumin Kinetics in Patients Undergoing Major Abdominal Surgery. PLoS ONE (2015) 10 (8): e0136371. doi:10.1371/journal.pone.0136371.

3. Nicholson J P et al. The role of albumin in critical illness. $\mathrm{Br} \mathrm{J}$ Anaesth 2000; 85: 599-610. 